\title{
Nicole Pellegrin (études réunies et présentées par),
} Histoires d'historiennes

Saint-Étienne, Publications de l'Université de Saint-Étienne, 2006, 403 pages.

Rebecca Rogers

\section{(2) OpenEdition}

Journals

Édition électronique

URL : http://journals.openedition.org/clio/7529

DOI : 10.4000/clio.7529

ISSN : 1777-5299

Éditeur

Belin

Édition imprimée

Date de publication : 1 janvier 2008

Pagination : 252-253

ISBN : 978-2-85816-973-3

ISSN : 1252-7017

Référence électronique

Rebecca Rogers, « Nicole Pellegrin (études réunies et présentées par), Histoires d'historiennes », Clio. Histoire, femmes et sociétés [En ligne], 27 | 2008, mis en ligne le 06 août 2008, consulté le 21 septembre 2020. URL : http://journals.openedition.org/clio/7529; DOI : https://doi.org/10.4000/clio. 7529

Ce document a été généré automatiquement le 21 septembre 2020.

Tous droits réservés 


\section{Nicole Pellegrin (études réunies et présentées par), Histoires d'historiennes}

Saint-Étienne, Publications de l'Université de Saint-Étienne, 2006, 403 pages.

\section{Rebecca Rogers}

Dans ce recueil ambitieux, Nicole Pellegrin questionne «l'invisibilité des praticiennes de l'histoire ». En faisant apparaître des "types d'oubliées d'écriture », les dix-neuf contributions d'auteures littéraires et historiennes révèlent une multitude de manières de faire de l'histoire depuis le $\mathrm{xv}^{\mathrm{e}}$ siècle et ouvrent des pistes pour mieux comprendre leur effacement d'une historiographie très masculine. Le résultat a certes un caractère " kaléidoscopique ", comme l'annonce Nicole Pellegrin dans ses propos liminaires, mais celui-ci constitue une richesse, invitant à des lectures plurielles à la fois des articles et des historiennes analysées.

2 C'est une belle initiative que de démarrer l'ouvrage par la traduction de l'article de Natalie Zemon Davis sur les femmes et l'écriture historique, article paru en anglais en 1980. En effet, dans ce questionnement sur le genre de l'histoire, la dette envers les Américaines, Nathalie Z. Davis et Bonnie Smith, est considérable ${ }^{1}$. L'article de la première montre les raisons qui ont poussé quelques femmes à l'époque moderne à faire des recherches puis à écrire sur le passé, les obstacles et contraintes qu'elles ont rencontrés dans cette quête, enfin la nature de cette écriture historique et de son évolution. Une fois le cadre posé, la suite du volume s'organise en trois temps d'abord des portraits de groupes, puis des études de cas, une première série sur l'Ancien Régime, une autre sur le long xix ${ }^{e}$ siècle.

Les portraits de groupes juxtaposent des historiennes rarement présentées ensemble sous cette appellation: les religieuses chroniqueuses de l'ordre des annonciades célestes de Liège au XVIII ${ }^{e}$ siècle, les auteures de dictionnaires et recueils de biographies féminines de la première moitié $\mathrm{du} \mathrm{XIX}^{\mathrm{e}}$ siècle, les historiennes du Répertoire méthodique de l'histoire moderne et contemporaine de Pierre Caron entre 1898-1902, celles du Centre 
de recherches historiques (CRH) entre 1966 et 1997 et enfin la place des historiennes dans la Bibliographie Annuelle de l'Histoire de France et de celles qui paraissent dans la rubrique historiographie de la BAHF entre 1953 et 2000. Portraits évidemment disparates qui marient comptage et tableau statistique avec l'analyse d'écritures historiques variées. La réhabilitation des historiennes religieuses ou des auteures de dictionnaires insiste sur le projet "politique " qui se dissimule derrière l'écriture féminine de l'histoire. Les autres contributions présentent plutôt un tableau du moment, font découvrir des noms, les qualités qui leur sont associées et leurs territoires de prédilection. Il est surtout question de la faible présence féminine, expliquée, dans le cas du Centre de recherches historiques, par la disparition publique du travail des « petites mains » dans les enquêtes collectives et par les jeux genrés de la cooptation dans les grandes entreprises récentes, que ce soit pour les Lieux de Mémoire ou dans les publications de l'Univers Historique.

Les articles qui présentent des études de cas s'ouvrent avec l'œuvre de Christine de Pizan, mais font aussi découvrir des formes de l'écriture historique moins étudiées comme les nouvelles historiques (avec $\mathrm{M}^{\mathrm{me}}$ de Villedieu et $\mathrm{M}^{\text {lle }}$ de la Roche-Guilhem), les romans historiques (avec $\mathrm{M}^{\mathrm{me}}$ de Genlis), la correspondance (avec Isabelle de Charrière), ou le glissement entre écriture historique et roman historique qu'on retrouve aussi bien sous la plume de la républicaine révolutionnaire Louise KéralioRobert, dans l'écriture d'Elisabeth-Pauline de Meulan Guizot, ou chez les auteures catholiques, Céline Fallet au $\mathrm{xIX}^{\mathrm{e}}$ siècle ou Jeanne Bourin au $\mathrm{xx}^{\mathrm{e}}$ siècle. La forte participation de littéraires induit des approches souvent centrées sur l'œuvre en ellemême -approches parfois difficiles à suivre pour la non-spécialiste - mais il est aussi largement question des modèles dans cette écriture féminine de l'histoire (bel article sur l'influence de $\mathrm{M}^{\mathrm{me}}$ de Staël), sur le caractère sexué de la transmission des connaissances historiques à l'école primaire, ou sur les raisons de l'effacement de certaines historiennes, comme Jeanne-Vielliard, cheville ouvrière de l'Institut de recherche et d'histoire des textes (IRHT). Cet ensemble foisonnant de plumes, de carrières et de voix redessine nos représentations de l'écriture historique et nous encourage à repenser la distinction, finalement peu heuristique, entre l'amateur et l'historien, distinction née avec la professionnalisation du métier à la fin du XIX siècle. La confrontation des approches littéraires et historiennes invite notamment à s'intéresser davantage aux genres de l'écriture, aux frontières mouvantes entre histoire et fiction, aux personnes se situant aux marges de l'institution universitaire. Enfin, ce livre montre bien que les enjeux d'une écriture genrée de l'histoire ont été perçus par les femmes bien avant la naissance officielle d'une histoire des femmes dans les années 1970.

\section{NOTES}

1. Voir Bonnie Smith, The Gender of History. Men, Women, and Historical Practice, Cambridge, Harvard University Press, 1998. 